\title{
EXTRACTION METHODS AND EXPERIMENT ON ESSENTIAL FOREST VARIABLES FOR GEOSPATIALLY-ENABLED SDGs MONITORING
}

\author{
ZHAO Yijing ${ }^{1,2}$, WU $\mathrm{Hao}^{2}$ \\ ${ }^{1}$ China University of Mining and Technology (Beijing), Beijing, 100083, China - 244706352@qq.com \\ ${ }^{2}$ National Geomatics Center of China, Beijing 100830, China- wuhao@ngcc.cn
}

KEY WORDS: Sustainable Development Goals, Geospatially-enabled monitoring, Essential forest variables, SDG Indicators, Global scale experiment, $0.2^{\circ}$ grids

\begin{abstract}
:
Since the United Nations passed the 17 Sustainable Development Goals (SDGs) and 169 sub-goals in 2015, many researchers have tried their best to put them into practise. However, mass data and different understanding of SDGs indicators make this work much more difficult. In this article we reference the concept of essential variables which may have some contribution to established a standard system for SDGs monitoring. Here we take SDG15 as an example. Firstly, we deeply analyse the main contents of SDG15 and select some geospatial-related indicators involved with forest land. From those forest-related and geospatial-enabled indicators we concise 5 essential forest variables (EFV4SDG15) which could be classified into 3 different types: land cover distribution and transformation, aggregative pattern and intensity and spatial-temporal evolution process. Secondly, formalized expression of EFV4SDG15 and extraction of them from multiple data source are necessary, including data processing and mathematical expression of the variables. Finally, we take global region as research target to carry out preliminary experiments. In this part, we only select 2 EFV4SDG15s: the forest coverage rate and forest land transfer matrix to show detailed operation process and then present the results in forms of figure and table. The paper has preliminary attempts to the application of essential variables in SDGs monitoring and provides an example for other fields.
\end{abstract}

\section{INTRODUCTION}

\subsection{Background}

With the rapid development of human process, the contradiction between human and society, economy and environment is increasingly prominent which has greatly hindered the implementation of sustainable development strategy. In order to draw more attention from governments, 193 member states of the United Nations passed the 17 Sustainable Development Goals (SDGs) containing 169 sub-goals at the United Nations Summit on Sustainable Development in 2015, and the term of execution shall be $15 \mathrm{y}$

ears. To facilitate monitoring and assessment, the Inter-Agency and Export Group on SDG Indicators (IAEG-SDGs) then proposed 232 targets.

Since SDGs was put forward, there has been many experts making great efforts for the early realization. Some researchers analysed the application of SDGs to ecological environment such as drought and biodiversity while some researchers applied SDGs to humanity such as education system. Even so there are still many difficulties. Mass data from different sources and different understanding of indicators among experts make the task full of challenges. The main priority now is setting a series of uniform standards or rules. Therefore, some researchers reference the concept of essential variables, which has been applied to other fields such as global climate observation, biodiversity observation and ocean observation. They come up with combining the essential variables with SDGs to establish a set of essential variables system related to society, economy and ecological environment. Through the analysis of SDG indicators, we find that many of them are closely related to land cover. For example, wetlands, rivers and lakes involved in sub-goal 6.6 and forest involved in sub-goal 15.1 all belong to the category of land cover. Concerning that SDG15 is the most concentrated application of land cover, especially forest, so here we choose SDG15 and essential forest variables as research subject.

\subsection{Research Targets (SDGs indicator)}

To select geospatially-enabled and forest-related indicators from SDG15, we firstly should know about the SDGs indicators that are closely related to geospatial information. Here we reference a list of SDGs Indicators where geospatial information had contribution developed by working group of geospatial information (IAEG-SDGs: WGGI) and extract the indicators included in goal 15 .

WGGI shows six indicators from SDG15 which relate to sustainable forest management, land degradation and biodiversity. Some indicators such as 15.1.1"Forest area as a proportion of total land" are directly associated with forest land while some indicators such as 15.4.1 "Coverage by protected areas of important sites for mountain biodiversity" have nothing to do with forest information. Here we determine to select 15.1.1, 15.2.1, 15.3.1 and 15.4.2 as our research targets.

\section{ESSENTIAL FOREST VARIABLES' DISTILLING}

\subsection{Deeply analysis of Indicators}

The UN system and some other organizations like Food and Agricultural Organization (FAO) established metadata repository for SDG indicators (https://unstats.un.org/sdgs/ metadata/).We deeply analyse the indicators through metadata repository and other approaches and then group indicators into 3 categories: sustainable forest management $(15.1 .1,15.2 .1)$, halt and reverse land degradation (15.3.1), halt biodiversity loss (15.4.2). Here we list the main content and precise definition for each indicator and sort out the intersection relationships 
between the forest land and indicators. Then we need to extract all relevant essential variables:

\section{I: Sustainable forest management}

15.1.1 Forest area as a proportion of total land area The crucial definitions about "Forest"and "Total Land Area" all come from metadata repository. Forest is defined as "land spanning more than 0.5 hectares with trees higher than 5 meters and a canopy cover of more than 10 percent, or trees able to reach these thresholds in situ. It does not include land that is predominantly under agricultural or urban land use". Total land area is "the total surface area of a country less the area covered by inland waters, like major rivers and lakes".

Forest contributes to the improvement of ecological environment and maintenance of biodiversity. The proportion of forest area in total land area can be used to measure forestland resources in a country or a specific area and. Actually the forest coverage rate can be directly used to represent the percentage of forest land in total land area.

15.2.1 Progress towards sustainable forest management The precise definition about sustainable forest management is "dynamic and evolving concept aims to maintain and enhance the economic, social and environmental values of all types of forests, for the benefit of present and future generations". Metadata repository divide this indicator into five sub-indicators. Here we just put first sub-indicator "Forest area annual net change rate" into consideration because data on other indicators are hard to come by.

To monitor the forest change comprehensively, we can spatialize the rate of forest change by GIS approach rather than traditional statistical one. Besides, there are some additional sub-indicators found in other literatures as supplements listed below:

i: Proportion of per capital forest area

ii:Area and proportion of forest land transferred to other land

The first indicator shows the average possession of forestland for a person in a country. The second indicator is the area and proportion of forest land transferred to other land.

\section{II: halt and reverse land degradation}

15.3.1 Proportion of land that is degraded over total land area This indicator contributes to measuring the proportion of degraded land area to total land area. Key information in indicator 15.3.1 is how to comprehend land degradation. Definition of land degradation comes from United Nations Convention to Combat Desertification (UNCCD). It means that" the reduction or loss of the biological or economic productivity and complexity of rainfed cropland, irrigated cropland, or range, pasture, forest and woodlands resulting from land uses or from a process or combination of processes arising from human activity." And metadata repository lists three sub-indicators for computation:

i: "assessment and evolution of land cover and land cover changes"

ii: "analysis of land productivity status and trends based on net primary production; and"

iii: "determination of carbon stock values and changes, with an initial assessment of soil organic carbon as the proxy."

Concerning that our task is to extract the essential variables associated with forest, we simplify the "land degradation" to "forest degradation" according to the definition of 15.3.1. Therefore, we should select information related to forest from these three sub-indicators listed above.

In addition, we also need to consult some professional definitions about "land degradation" in the relevant literatures. The final criteria for forestland degradation are as follows:

i: Bare land that was transferred from forest land

ii: Area with high degree of fragmentation of forest land

The transfer of forest land to bare land is the main manifestation of forest's desolation. Driving factors of this phenomenon may be deforestation and hill fire. So the first index can partly reflect forest degradation. Moreover, the fragmentation of landscape such as number of patches also can be used to measure land degradation.

\section{III: halt biodiversity loss}

15.4.2 Mountain green cover index

This indicator is aimed to measure the change of green vegetation in mountain areas and reflects the ecological environment of mountain areas. It is directly related with mountain biodiversity. Green cover index can be calculated by the proportion of green vegetation area to total area. Concerning that forest is the main green vegetation in mountain area, so this indicator can be calculated by the percentage of forest in total area.

\subsection{Definition of EFV4SDG15}

From above analysis we can refine 5 EFV4SDG15:

$\mathrm{V}_{1}$ : forest coverage rate

$\mathrm{V}_{2}$ : forest area annual net change rate

$\mathrm{V}_{3}$ : per capital forest area

$\mathrm{V}_{4}$ : degree of fragmentation of forest

$\mathrm{V}_{5}$ : forest land transfer matrix

The first variable $V_{1}$ "forest coverage rate" is a key element of sustainable forest management and can be used to reflect the degree of greening in a country. It is refined from SDGs indicator 15.1.1 and 15.4.2. $\mathrm{V}_{2}$ "forest area annual net change rate" comes from 15.2.1. It can be used to show the intensity of change of forest land. $\mathrm{V}_{3}$ "per capital forest area" is refined from 15.2.1 which is closely related to sustainable forest management. The higher proportion of per capital forest area, the richer the national forest resources, the more conducive to the sustainable forest development. $\mathrm{V}_{4}$ "degree of fragmentation of forest" is related with 15.3.1. A region with little forest area loss but higher fragmentation is not productive. That's the reason why we select it as one of the essential variables. $V_{5}$ "forest land transfer matrix" is the area and proportion of forest land transferred to other land. And it can assist us understanding the driving factors led to forest's disappearance and realizing the forest land's water and soil conversation capacity. We refine it from 15.2.1 and 15.3.1.

Now we should define them with 3 different types: land cover distribution and transformation $\left(\mathrm{T}_{1}\right)$, aggregative pattern and intensity $\left(\mathrm{T}_{2}\right)$ and spatial-temporal evolution process $\left(\mathrm{T}_{3}\right)$. The association table is as follow

\begin{tabular}{|c|c|c|c|}
\hline \multicolumn{2}{|c|}{ EFV4SDG15 } & Related SDGs \\
indicators
\end{tabular}




\begin{tabular}{|lll|l|} 
& & $\mathrm{V}_{2}$ & 15.2 .1 \\
$\mathrm{~V}_{3}$ & & & 15.2 .1 \\
& & & 15.3 .1 \\
& $\mathrm{~V}_{4}$ & & 15.2 .1 \\
$\mathrm{~V}_{5}$ & & & 15.3 .1 \\
\hline
\end{tabular}

Table1. The association table between indicators and variables

\section{EXTRACTION OF EFV4SDG15}

We have known the definition of these essential variables. And then we should move on discussing the expression of mathematical formulas to make it more intuitive.

\subsection{Acquisition of Foundation Data}

The variables we distilling are geospatially-enabled. Just leading to statistical data from countries' reports is not enough. We have to seek for other accesses. Technology of remote sensing not only provided an efficient and convenient method for us to get the land cover information including forest information but also offer the spatial reference. It can help researchers to monitor SDGs indicators more comprehensively. The remote sensing images such as Landsat and MODIS are available free of charge in United States Geological Survey (USGS, https://earthexplorer.usgs.gov/).

In addition to the geospatial information that is related with forest, we need social statistics such as the population of each country which can be got from World Bank (https://data. worldbank.org.cn/) and vector data such as administrative boundary.

\subsection{Mathematical Expressions}

i: forest coverage rate

Forest coverage rate is the proportion forest area to total land area. It can directly reflect inindicator15.1.1 and partly reflect indicator 15.4.2. The mathematical formula is as follows:

$$
v_{1}=\frac{F A_{y}}{L A_{y}} \times 100 \%
$$

where $\quad v_{l}=$ forest coverage rate

$$
F A_{y}=\text { thforest area at the year of } y
$$

$L A_{y}=$ total land area except inland water at the year of $\mathrm{y}$

ii: forest area annual net change rate

Forest area annual net change rate express the change rate of forest land. In order to calculate this indicator, we need at least two years' data. It's calculation formula is as follow:

$$
v_{2}=\left(\frac{F A_{y_{2}}}{F A_{y_{1}}}\right)^{\frac{1}{\left(y_{2}-y_{1}\right)}}-1
$$

where $\quad v_{2}=$ forest area annual net change rate;

$F A_{y_{2}}=$ forest area at end year

$F A_{y_{1}}=$ forest area at starting year

$y_{1}, y_{2}=$ starting year and end year

iii: Per capital forest area

This indicator reflect the average area of forest owned by each person. Here we should add the demographic data into calculation:

$$
v_{3}=\frac{F A_{y}}{P O P_{y}}
$$

where

$$
v_{3}=\text { per capital forest area }
$$

$F A_{y}=$ forest area in the year of $y$

$P O P_{y}=$ the population in the year of $y$ iv: forest land transfer matrix

Land cover transfer matrix was developed from Markov model. This matrix can not only quantitatively show the transformation between different land use types, but also reveal the transfer rate. Generally, the land cover matrix is generated by the overlay analysis of two classification raster images and possesses spatio-temporal characteristics. The land cover transfer matrix is represented by a table:

\begin{tabular}{|c|cccccc|}
\hline initia\ final & $L C_{1}$ & $L_{2}$ & --- & $L C_{x}$ & --- & $L C_{n}$ \\
\hline $\mathrm{LC}_{1}$ & $A_{11}$ & $A_{12}$ & --- & $A_{1 x}$ & --- & $A_{l n}$ \\
$\mathrm{LC}_{2}$ & $A_{21}$ & $A_{22}$ & --- & $A_{2 x}$ & --- & $A_{2 n}$ \\
$\vdots$ & $\vdots$ & $\vdots$ & $\vdots$ & $\vdots$ & $\vdots$ & $\vdots$ \\
$\mathrm{LC}_{\mathrm{y}}$ & $A_{y 1}$ & $A_{y 2}$ & --- & $A_{y x}$ & --- & $A_{y n}$ \\
$\vdots$ & $\vdots$ & $\vdots$ & $\vdots$ & $\vdots$ & $\vdots$ & $\vdots$ \\
$\mathrm{LC}_{\mathrm{n}}$ & $A_{n 1}$ & $A_{n 2}$ & --- & $A_{n x}$ & --- & $A_{n n}$ \\
\hline
\end{tabular}

Table2. Land use transfer matrix

where $\quad L C=$ different land cover class

$x, y=$ type of land cover

$n=$ total classes of land cover

$L C=\mathrm{A}_{\mathrm{yx}}$ : land area of class $\mathrm{y}$ to class $\mathrm{x}$.

initial=the initial state

final $=$ the final state

Concerning that we only need the forest transformation, we just calculate the area of forest land transferred to other land classes and the area of other land classes transferred to forest.

$\mathbf{v}$ : degree of fragmentation of forest

We always use the number of patches per unit area to represent this indicator. Patch is the basic component unit of landscape pattern. The greater the number of patches in a statistical unit, the higher the degree of fragmentation. Land scape fragmentation can be used to evaluate land productivity. It also reflects the degree of human interference with the land. It's calculation formula is as follow:

$$
v_{5}=\frac{N_{i}}{A_{i}}
$$

where $\quad v_{5}=$ the degree of forest fragmentation

$$
\begin{aligned}
& N_{i}=\text { the number of patches in statistical unit } \\
& A_{i}=\text { area of statistical unit }
\end{aligned}
$$

\section{EXSPERIMENT ON GLOBAL SCALE}

In this section, we operated the experiment and demonstrated how to spatialized the essential variables. Here we just take "forest coverage rate" and "forest land transfer matrix" as examples.

\subsection{Material and Data Processing}

Our classified image comes from GlobeLand30 which is the first remote sensing mapping data set for globe land cover with a $30 \mathrm{~m}$ resolution. This data set includes ten classes: grass land, forest land, bare land, cultivated land and so on. It's overall precision comes up to $83.50 \%$. In our experiment, we can get the distribution of forest from GlobeLand30 and then calculate forest area or other information we need.

\section{The spatialization of forest coverage rate}

In order to make the essential forest variables geospatial characteristics, we divided the global land into $0.2^{\circ}$ grids. And then calculate the forest coverage rate in each grid. 
Forest land transfer matrix of each continent

Through land transfer matrix we can know about where the reduced forest transferred to and which classes of land cover turned to forest. In the experiment we choose two years of GlobeLand30 data set: 2000 and 2010 and then overlaid them to generate forest land transfer matrix of each continent.

\subsection{Results}

Here we present the results in the form of figure and table. The forest coverage rate is shown in Figure 1. And the transformation of forest land is shown in Table 3 and Table 4.



Figure1: The forest coverage rate with 0.2 degree grids in 2010 .

\begin{tabular}{|l|lllllllll|}
\hline continent & $\begin{array}{c}\text { cultivated } \\
\text { land }\end{array}$ & grass & shrub & wet land & water & tundra & artificial & bare land & glacier \\
land & & & \\
\hline South America & 97360.80 & 252698.39 & 133375.49 & 30980.15 & 7446.18 & 0.00 & 1710.69 & 2188.30 & 703.89 \\
Oceania & 15795.04 & 251346.00 & 99559.11 & 4352.34 & 2430.78 & 0.00 & 804.60 & 4165.41 & 177.60 \\
North America & 44618.84 & 177555.85 & 225215.02 & 41484.14 & 29631.77 & 275378.99 & 8323.36 & 13694.41 & 1978.02 \\
Europe & 55518.80 & 25465.27 & 65700.32 & 4832.69 & 7093.50 & 5443.88 & 4592.52 & 821.09 & 42.25 \\
Asia & 85458.89 & 433348.28 & 37541.84 & 36094.11 & 18353.79 & 22075.81 & 5138.32 & 10093.29 & 630.78 \\
Africa & 173226.45 & 2359675.40 & 571067.36 & 19227.87 & 4569.18 & 0.00 & 3427.37 & 27004.03 & 0.05 \\
\hline
\end{tabular}

Table3: Area that forest transferred to other lands (unit: $\mathrm{km}^{2}$ )

\begin{tabular}{|l|cllllllll|}
\hline continent & $\begin{array}{c}\text { cultivated } \\
\text { land }\end{array}$ & grass & shrub & wet land & Water & tundra & $\begin{array}{c}\text { artificial } \\
\text { land }\end{array}$ & bare land & glacier \\
\hline South America & 35843.41 & 194826.24 & 325847.80 & 36232.21 & 11425.40 & 0.00 & 1164.19 & 2080.93 & 539.40 \\
Oceania & 14257.44 & 165070.56 & 66294.52 & 6118.01 & 3410.93 & 0.00 & 488.71 & 6148.42 & 15.22 \\
North America & 41932.55 & 164838.47 & 192741.60 & 58470.98 & 33975.07 & 102540.98 & 4950.42 & 9066.86 & 3271.98 \\
Europe & 50372.63 & 26494.63 & 12712.94 & 8568.69 & 10793.02 & 5000.14 & 3975.21 & 769.73 & 547.22 \\
Asia & 64676.50 & 371365.66 & 29013.92 & 23026.95 & 16463.89 & 25296.70 & 3846.51 & 142362.32 & 2823.56 \\
Africa & 60634.68 & 528188.67 & 64227.21 & 18516.17 & 6090.03 & 0.00 & 882.07 & 1945.88 & 0.02 \\
\hline
\end{tabular}

Table4: Area that other lands transferred to forest (unit: $\mathrm{km}^{2}$ )

\section{CONCLUSION}

This paper distilled essential forest variables from SDG15. Our work has some contribution on the SDGs monitoring and provides the idea for the researches in other fields. Main work can be summarized as the following points:

i: We study the main concept about the indicators of SDG15 and then select the forest-related SDGs indicators where geospatial information has contribution.

ii: Refining the essential forest variables from the indicators we select in step i.

iii: The extraction of essential variables.

iv: In order to implement the ideas proposed in this article, we take global area to carry out preliminary experiments.

Despite we consulted many literatures and paid a lot of efforts, there are still some shortcomings in this article:

$\mathrm{i}$ : The understanding of indicators is not thorough enough. We study these indicators in approach of metadata repository generated by the United Nations. This is not necessarily the most comprehensive expression.

ii: some variables are not extracted because of the unavailable data and limitation of understanding such as carbon stock values. iii: We just present how to extract essential variables and there is no modelling involved.

\section{REFERENCES}

Yang, H. X., Chen, X., 2019. Study on the economic applicability of urban environmentally sustainable development policy. Advances in Economics, Business and Management Research, volume 80. doi.org/10.2991/ bems-19.2019.69

Bernard, J, 2019. Where have all the rural poor gone? explaining the rural-urban poverty gap in european countries. Sociologia Ruralis. doi: 10.1111/soru.12235, 369-392.

Wu, W., Shi, J. L., 2017. German sustainable development model. Deutschland-Studien, 4-24+124.

Chen, J., Ren, H. R., Geng, W., 2018. Quantitative measurement and monitoring sustainable development goals (SDGs) with geospatial information. GEOMATICS WORLD, 25(1):1-7.

Chang, Y., Wang, J. P., et al., 2018. Progress and prospects of China's implementation of the 2030 agenda for sustainable development. Water Resources Development Research, 18(11), 69-73, doi: 10.13928/j.cnki.wrdr.2018.11.018

Chen, J., Peng, S., Zhao, X. S., et al., 2019. Measuring regional progress towards SDGs by combining geospatial and statistical 
information. Acta Geodaetica et Cartographica Sinica, 48(4): 473-479. doi: 10.11947/ j. AGCS. 2019. 20180563

Zhang, X., Chen, N., Sheng, H., et al., 2019. Urban drought challenge to 2030 sustainable development goals. Science of theTotal Environment. doi.org/10.1016/j. scitotenv.2019.07.342

Xu, J., Geng, Y. J., Yin, S. L., et al., 2018. A study on elements of post-2020 global biodiversity framework based on sustainable development goals. Environmental Protection . 46(23),17-2. doi:10.14026/j.cnki.0253-9705.2018.23.004.

Wang, J. L., Cheng, K., Bian, L. L., et al., 2018. Integration framework and key technology of big earth data for SDGs and beautiful China evaluation. Remote Sensing Technology and Application,33(5):775-783. doi:10.11873/j.issn.1004-0323. 2018 . 5.0775.

Turak, E., Brazil-Boast, J., Cooney, T., et al., 2017. Using the essential biodiversity variables framework to measure biodiversity change at national scale. Biological Conservation, 213(2017) 264-271. doi.org/10.1016/j.biocon.2016.08. 019 .

Bojinski, S., Verstraete, M., Peterson, T. C., 2014. The concept of essential climate variables in support of climate research, application, and policy. AMERICAN METEOROLOGICAL SOCIETY, 1431-1443.

Geng, W., Chen, J., Zhang, H. P., Xu, K., 2018. Task and progress of IAEG-SDGs: WGGI in monitoring SDGs through a 'geographic location' lens. The International Archives of the Photogrammetry, Remote Sensing and Spatial Information Sciences, Volume XLII-3, 2018.doi.org/10.5194/isprs-archivesXLII-3-385-2018.

Food and Agriculture Organization of the United Nations, 2015.Global forest resources assessment (FRA) 2015. [Available online at http:// www.fao.org/ forest-resourcesassessment / en/.]

Hong, H. S., Yue, S. P., 2000: Criteria and Indicators of Sustainable Management in Canada. WORLD FORESTRY RESEARCH, 2000(05): 57-61. doi: 10.13348/j.cnki.sjlyyj. 2000.05 .010

Zhang, P., Sun, Q. Q., Sun D. F., 2019: Establishment of land degradation assessment system in arid region based on remote sensing spectrum. Transactions of the Chinese Society of Agricultural Engineering (Transactions of the CSAE),35(9): 228-237. doi: 10.11975/ j. issn.1002-6819.2019.09.028

Yu, Q. Y., Hu, Q., Vliet, J. V., 2017: GlobeLand30 shows little cropland area loss but greater fragmentation in China. International Journal of Applied Earth Observations and Geoinformation, doi.org/10.1016/j.jag.2017.11.002.

Wu, X. W., 2018: Landscape patter dynamics evolution and eco- security assessment in the small sanjiang plain. Wuhan University.

Kussul, N., Lavreniuk, M., Kolotii, A., et al., 2019: A workflow for Sustainable Development Goals indicators assessment based on high-resolution satellite data. International Journal of Digital Earth. doi.org/10.1080/17538947.2019.1610807.

Honeck, E., Castello, R., Chatenoux, B., et al., 2018: From a vegetation index to a Sustainable Development Goal Indicator:
Forest trend monitoring using three decades of earth observations across Switzerland. International Journal of GeoInformation. doi:10.3390/ijgi7120455.

Fu, G., Xiao, N. W., Qiao, M. P., 2017: Spatialtemporal changes of landscape fragmentation patterns in Beijing in the last two decades. Acta Ecologica Sinica, 2017, 37( 8) : 25512562. doi : 10.5846/ stxb201510232141.

Chen, J., Liao, A. P., Chen, J., 2017: 30-Meter Global Land Cover Data Product- GlobeLand30. GEOMATICS WORLD, 24(1):1-8. 